\title{
Spatiotemporal characteristics of Qinghai Lake ice phenology between 2000 and 2016
}

\author{
QI Miaomiao, 'YAO Xiaojun, LI Xiaofeng, DUAN Hongyu, GAO Yongpeng, \\ LIU Juan \\ College of Geography and Environment Sciences, Northwest Normal University, Lanzhou 730070, China
}

\begin{abstract}
Lake ice phenology is considered a sensitive indicator of regional climate change. We utilized time series information of this kind extracted from a series of multi-source remote sensing (RS) datasets including the MOD09GQ surface reflectance product, Landsat $\mathrm{TM} / \mathrm{ETM}+$ images, and meteorological records to analyze spatiotemporal variations of ice phenology of Qinghai Lake between 2000 and 2016 applying both RS and GIS technology. We also identified the climatic factors that have influenced lake ice phenology over time and draw a number of conclusions. First, data show that freeze-up start (FUS), freeze-up end (FUE), break-up start (BUS), and break-up end (BUE) on Qinghai Lake usually occurred in mid-December, early January, mid-to-late March, and early April, respectively. The average freezing duration (FD, between FUE and BUE), complete freezing duration (CFD, between FUE and BUS), ice coverage duration (ICD, between FUS and BUE), and ablation duration (AD, between BUS and BUE) were 88 days, 77 days, 108 days and 10 days, respectively. Second, while the results of this analysis reveal considerable differences in ice phenology on Qinghai Lake between 2000 and 2016, there has been relatively little variation in FUS times. Data show that FUE dates had also tended to fluctuate over time, initially advancing and then being delayed, while the opposite was the case for BUS dates as these advanced between 2012 and 2016. Overall, there was a shortening trend of Qinghai Lake's FD in two periods, 2000-2005 and 2010-2016, which was shorter than those seen on other lakes within the hinterland of the Tibetan Plateau. Third, Qinghai Lake can be characterized by similar spatial patterns in both freeze-up (FU) and break-up (BU) processes, as parts of the surface which freeze earlier also start to melt first, distinctly different from some other lakes on the Tibetan Plateau. A further feature of Qinghai Lake ice phenology is that FU duration (between 18 days and 31 days) is about 10 days longer than BU duration (between 7 days and 20 days). Fourth, data show that negative temperature accumulated during the winter half year (between October and the following April) also plays a dominant role in ice phenology variations of Qinghai Lake. Precipitation and wind speed both also exert direct influences on the formation and
\end{abstract}

Received: 2018-02-07 Accepted: 2018-03-28

Foundation: Opening Foundation Project of the State Key Laboratory of Cryosphere Sciences, CAS, SKLCS-OP-2016-10; National Natural Science Foundation of China, No.41261016, No.41561016; Youth Scholar Scientific Capability Promoting Project of Northwest Normal University, No.NWNU-LKQN-14-4

Author: Qi Miaomiao (1993-), Masters Candidate, specialized in research on lake ice phenology. E-mail: qimiaomiao_mzl@163.com

"Corresponding author: Yao Xiaojun (1980-), PhD and Associate Professor, specialized in research on GIS and cryospheric changes. E-mail: xj_yao@nwnu.edu.cn 
melting of lake ice cover and also cannot be neglected.

Keywords: lake ice; phenology; freeze-up and break-up; MODIS; Qinghai Lake

\section{Introduction}

The global climate change has been profoundly influenced by both human development and survival and is one of the major challenges currently faced by the international community (Vaughan et al., 2013). It is well known that there is a strong link between climate change and the phenology of lake ice (Weber et al., 2016); as freeze-up and break-up durations accurately record changes in regional climate, lake ice phenology is considered to be a significant indicator of regional climate change (Johnson et al., 2006; Marszelewski et al., 2006; Qin, 2012; Benson et al., 2012; Vaughan et al., 2013). As lake ice is also an important component of the cryosphere, annual changes in this variable also influence the regional heat and energy balance and are also of important ecological and economic value (Weyhenmeyer et al., 2004; Duguay et al., 2006; Xin et al., 2008; Qin, 2012). The uplift of the Tibetan Plateau has also had a significant influence on the natural environmental evolution of the plateau and its adjacent areas, while regional climate change is known to be closely related to global climate change. Indeed, more local variations are often referred to as "the driver and amplifier of global climate change" (Pan, 1996). It is also the case that the Tibetan Plateau encompasses both the largest number of plateau lakes at the highest altitudes globally (Duguay et al., 2006); there are 1055 such lakes on the plateau that cover an area of $41,831.7 \mathrm{~km}^{2}$ (Ma et al., 2011). As most areas on the Tibetan Plateau are inaccessible because of the harsh environment of this region, lakes are rarely influenced by human activities and largely remain in their natural states. This also means that the phenology of lake ice can be used as an accurate proxy for natural regional climate change. Analyses that address the spatiotemporal characteristics of lake ice phenology on the Tibetan Plateau in the context of global warming are therefore of great significance, not only to develop more accurate picture of these variations locally, but also to promote a deeper understanding of climate change in this region. The phenology of lake ice on the Tibetan Plateau has therefore attracted considerable national and international research attention in recent years (Kropáček et al., 2013).

At present, the research on the lake ice phenology has mostly extracted time and attribute parameters (Wei et al., 2010), which are usually collected using ground observations and remote sensing (RS) monitoring. The first of these approaches is high-precision but is also time-consuming and laborious, while RS monitoring can encompass a larger range of observations and has a higher update speed. These attributes compensate for the drawbacks inherent to ground-based observations including the potential use of artificial samples, weather stations, and other unevenly distributed data. As the development of RS techniques has enabled researchers to obtain lake ice phenology using automatic (or semi-automatic) approaches, this suite of methods has gradually become the most common for lake surface ice observations (Hall et al., 2002; Lenormand et al., 2002; Latifovic et al., 2007). Research around the world on lake ice phenology has so far mainly been carried out in central and northeastern North America and in northern Europe (Magnuson et al., 2000; Benson et al., 2012; Wang et al., 2012) and has focused on establishing datasets in this area, simulating the evolution of ice using mathematical models, and assessing the responses of these surfaces to 
global climate change (Wang et al., 2010; Dibike et al., 2012; Oveisy et al., 2014). Research in this area has therefore contributed important international data to the Intergovernmental Panel on Climate Change. In contrast, research on lake ice phenology within China has mainly focused on the great Tibetan Plateau lakes; previous research in this area has shown that reductions in lake freezing durations on the Tibetan Plateau are due to delayed freeze-up times and the advance of break-up times (Che et al., 2009; Ke et al., 2013; Yao et al., 2015). One example, Qinghai Lake, is located at the junction between the East Asian and Indian monsoons and the westerlies (Ma et al., 2011) and so is very sensitive to climate change; the phenology of lake ice at this site has gradually attracted more and more attention from researchers. In early work, Chen et al. (1995) investigated changes in Qinghai Lake ice phenology using an inversion between 1958 and 1983 based on AVHRR satellite images, while Ying et al. (2005) later performed a water surface temperature inversion using EOS/MODIS satellite images to establish a monitoring model for this site. Che et al. (2009) developed a complete sequence for Qinghai Lake ice phenology between 1978 and 2006 using SSM/I data, revealed that ice cover duration has decreased by between 14 days and 15 days over this time, and showed that the date of ice break-up is most sensitive to changes in regional temperature. Although Cai et al. (2017) attempted to analyze ice phenology on Qinghai Lake between 1979 and 2016 using both SMMR and SSM/I data, the low spatial resolution and discontinuities in these data limited the extraction of relevant information. Thus, as the area of this lake is expanding and its water level is rising, it is increasingly important to determine how changes in the phenology of lake ice respond to climate change. We therefore established a series of Qinghai Lake ice phenology datasets for the period between 2000 and 2016 using both RS and GIS technology; these datasets enable us to provide references for winter tourism, lake navigation, and ice thickness inversions as we analyze Qinghai Lake freeze-melt processes in detail.

\section{Study area}

Qinghai Lake $\left(36.53^{\circ}-37.25^{\circ} \mathrm{N}, 99.60^{\circ}-100.78^{\circ} \mathrm{E}\right)$ is located on the northeastern Tibetan Plateau within the Tibetan Autonomous Prefecture of Hainan in Qinghai Province. This waterbody is the largest inland saltwater lake within China (Figure 1), and was formed as a result of a stratigraphic fault depression which means that its northwestern part is at a higher elevation than the southeastern. The Haixin Mountain and Three Stone islands are in the center of this lake, and the whole feature is surrounded by a series of sub-lakes, including Gahai, Haiyan Bay, and Shadao on the eastern shore and Erhai Lake on the southeastern margin. Data collected in 2013 shows that Qinghai Lake encompasses an area of $4294 \mathrm{~km}^{2}$ (Figure 1) and has an elevation of approximately $3200 \mathrm{~m}$; this feature is slightly "convex" in overall shape, measuring about $109 \mathrm{~km}$ east-to-west and $65 \mathrm{~km}$ north-to-south with an average water depth of about $18.3 \mathrm{~m}$. The water level of Qinghai Lake has been rising in recent years as the volume of glacial melt water from the Qilian Mountains has increased alongside precipitation within the Qinghai Lake Basin; these factors have also increased the area of the lake (Dong and Song, 2011; Wan et al., 2014). Measurements made over many years show that the lake basin is characterized by a cold and arid continental climate including a low annual temperature but large variations in daily average values that range between $-1.4^{\circ} \mathrm{C}$ 
and $1.7^{\circ} \mathrm{C}$, gradually decreasing from southeast to northwest (Sun et al., 2007). Mean annual precipitation within the lake basin tends to be concentrated in the summer and is between $319 \mathrm{~mm}$ and $395 \mathrm{~mm}$; these data also reveal that rainfall in the southwestern part of the ba$\sin$ is less than in the northeastern and that precipitation gradually is increasing from the center to the ambitus of the lake (Li et al., 2008). The major rivers that fed into the Qinghai Lake Basin include the Buha and Shaliu; these systems form an obviously asymmetric distribution such that the flow in the northwest is larger than that in the southeast. Alpine meadows and steppe are also widely distributed within the Qinghai Lake Basin; this region comprises an important biological center within the Tibetan Plateau because of an abundance of species and unique natural conditions, often referred to as the "Gene Pool of Tibetan Plateau".

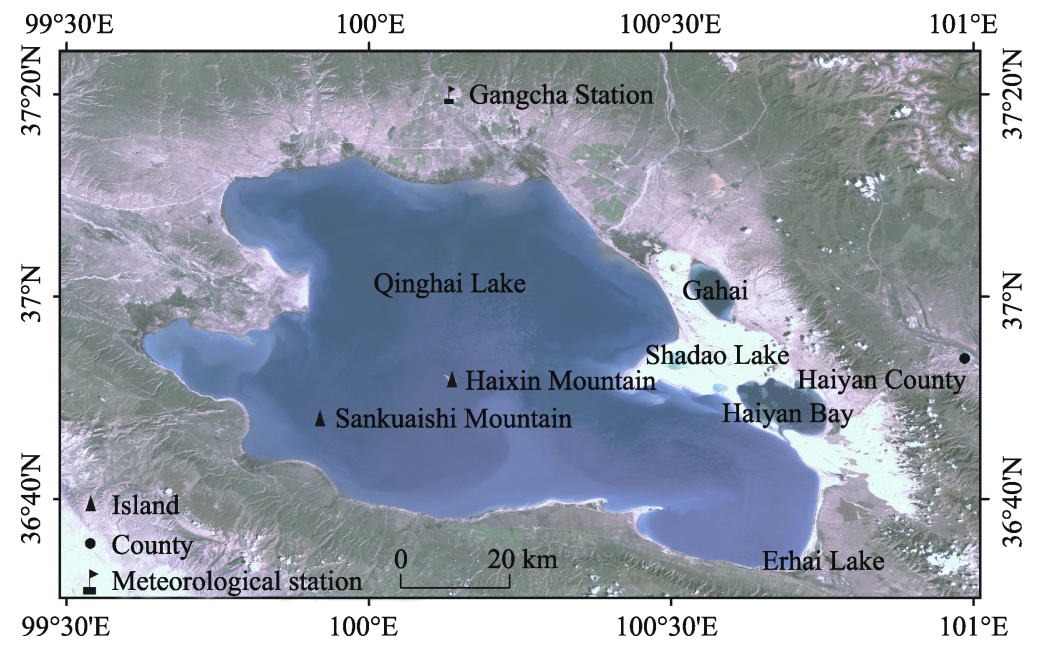

Figure 1 A Landsat TM image base map showing the study area discussed in this paper

\section{Data and methods}

\subsection{Data}

In order to accurately obtain data on the timing of Qinghai Lake ice formation and decay, MODIS MOD09GQ products at high temporal (one day) and moderate spatial resolutions (i.e., $250 \mathrm{~m}$ on bands 1 and 2 and $500 \mathrm{~m}$ on bands 3 and 4) were utilized in this study. A total of 12,410 scenes for the period between 2000 and 2016 were therefore downloaded from the website (https://data.giss.nasa.gov) of the National Aeronautics and Space Administration Land Surface Distributed Data Center and used to monitor Qinghai Lake freezing-ablation processes. We wrote a batch script in Python to perform geometric corrections of MODIS 1B data in order to deal with a large number of images, selected UTM projections and the WGS84 coordinate system, and calculated the area ratio between lake and ice by inputting multi-scene images. We statistically analyzed all images that were cloudless via visual interpretation one-by-one, focusing in particular on a series of 34 Landsat TM/ETM+ image scenes that had a spatial resolution of $30 \mathrm{~m}$ to verify the accuracy of lake ice phenology data extracted from MODIS MOD09GQ and Landsat data provided by the USGS and NASA 
(http://earthexplorer.usgs.gov).

In the absence of more widespread information, we utilized wind speed and temperature data collected at Gangcha meteorological station relatively close to Qinghai Lake as a reference for the regional climatic background. Because of the complexity of the Tibetan Plateau both in terms of terrain and changeable climate, we employed $0.5^{\circ} \times 0.5^{\circ}$ temperature and precipitation grid data as a supplement generated from observational records collected at all national meteorological stations and via a GTOPO30 digital elevation model. All these data were downloaded from the website of the Chinese Meteorological Information Center (http://data.cma.cn).

\subsection{Automated lake ice extraction}

Identifying lake ice using RS is dependent on the spectral characteristics of ice and water and is mainly assessed via artificial visual interpretation and use of the threshold and index methods (Reed et al., 2009; Choinski et al., 2010; Wei and Ye, 2010). The last of these, the index method, is an indirect approach that applies band calculations to distinguish the two, while the threshold method is more direct and synthetically takes into account reflectivity, temperature, the backward scattering coefficient, as well as other characteristics of lake ice and water. This approach can therefore provide a higher precision result by eliminating atmospheric influences and system errors (Wei and Ye, 2010). We therefore used the threshold method to extract lake ice phenology information in this study by defining a threshold between the red and near-infrared bands. The calculation equation used in this analysis is as follows (Yin and Yang, 2005):

$$
\text { Results }=\left\{\begin{array}{l}
\text { lake ice, } \quad \text { if } \rho_{\text {red }}-\rho_{N I R}>a \text { and } \rho_{\text {red }}>b \\
\text { no lake ice, if } \rho_{\text {red }}-\rho_{\text {NIR }}<a \text { or } \rho_{\text {red }}<b
\end{array}\right.
$$

In this expression, $\rho_{\text {red }}$ and $\rho_{N I R}$ denote the reflectance of the red and near-infrared bands, respectively, and correspond with MODIS MOD09GQ Band 1 and Band 2. We combined with artificial visual interpretations and histogram distributions to determine appropriate thresholds using repeated human-computer interaction tests. Thus, two thresholds ( $a$ and $b$ ) were used to distinguish lake ice from surrounding water, 0.028 and 0.05 , respectively.

The Landsat ETM+ and MODIS images presented in Figure 2 show the status of Qinghai Lake on February 22nd, 2014. These images estimated for ice cover area at this time of $4125.66 \mathrm{~km}^{2}$ (based on artificial visual interpretation of the Landsat ETM+ image) (Figure 2a) and $4092.17 \mathrm{~km}^{2}$ (using the threshold method applied to MODIS MOD09GQ data (Figure $2 b$ ). As the error of the latter estimate was only $0.8 \%$, it is clear that the threshold method performed much better in this case.
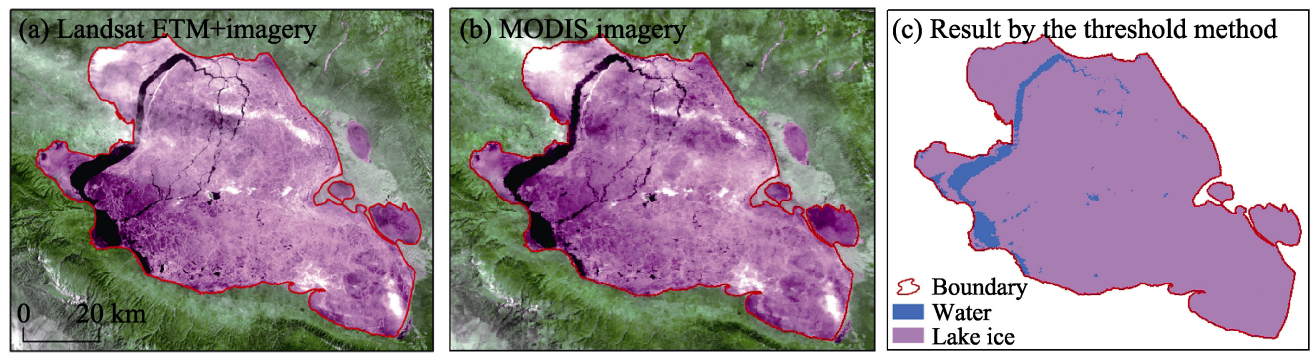

Figure 2 Images showing ice cover on Qinghai Lake on February 22nd, 2014 


\subsection{Automated identification of lake ice phenology}

The ice coverage duration (ICD) over time period of this research was defined as the number of days between lake freeze-up start (FUS) and ice break-up end (BUE). Thus, ice ablation duration (AD) encompasses the period between break-up start (BUS) and BUE. As discrepancies exist in the definition of variables used to describe the duration of lake ice cover, comparisons between phenology records for different regions are often biased (Reed et al., 2009; Kropáček et al., 2013; Gou et al., 2015); we therefore used freezing duration (FD, between FUE and BUE) and complete freezing duration (CFD) to describe ice phenology on Qinghai Lake in this study. The former (FD) is defined as the time interval between lake freeze-up end (FUE) and ice BUE, while CFD refers to the time between lake FUE and ice BUS. As the lake generally freezes in the autumn or winter, and begins to melt during the following spring or summer each year (Che et al., 2009), these dates reflect changing trends in ice phenology. Thus, in order to accurately obtain the timing of formation and decay in ice cover, the freeze-up date was defined as the time point when ice cover is greater than, or equal to, $90 \%$ of lake area, while break-up date was defined as the time point when ice was less than, or equal to, $10 \%$ of total cover (Reed et al., 2009). These assumptions mean that lake ice phenology parameters could be automatically extracted, as follows:

$$
\text { Results }=\left\{\begin{array}{l}
F U S, \text { if } I A \geqslant 0.1 * L A \\
F U E, \text { if } I A \geqslant 0.9 * L A \\
B U S, \text { if } I A \geqslant 0.9 * L A \\
B U E, \text { if } I A \geqslant 0.1 * L A
\end{array}\right.
$$

In this expression, $L A$ and $I A$ refer to lake and ice areas, respectively. $I A$ value was calculated using GIS software from automatically extracted lake ice data (see above), while $L A$ value was based on annual lake boundary results for the period between 2000 and 2016 .

\section{Results and discussion}

\subsection{Temporal characteristics of lake ice phenology}

The ice phenology of Qinghai Lake between 2000 and 2016 are presented in Table 1. These data show that the temporal characteristics of lake ice phenology include a few diurnal scale inaccuracies for some years because of the influence of cloud cover; the maximum error over the period of this research was 3 days in the worst case. Dates for FUS were relatively concentrated over the study period, and mainly occurred in mid-December each year; while the average FUS date was December 16th each year (the 350th day of the year) this phenomenon occurred earliest on December 6th, 2005 (the 340th day of the year), and latest on December 28th, 2004 (the 362nd day of the year). The average time between FUS and FUE was about 20 days; the date of FUE was either at the end of December or in early January of the following year, while the average FUE date was January 5th (the 5th day of the year), and the earliest and latest FUE dates, respectively, occurred on December 23rd, 2005 (the 357 th day of the year) and January 23rd, 2009 (the 23rd day of the year). Data show that BUE occurred in late March after two or three months CFD, the average BUS date was March 23rd (the 82nd day of the year), and the earliest and latest BUS dates, respectively, 
were on March 2nd, 2015 (the 62nd day of the year) and April 7th, 2008 (the 97th day of the year). The termination of lake ice break-up usually occurred between late March and early April within about ten days of AD, while the average BUE date was April 11th (the 93rd day of the year) with the earliest and latest dates occurring on March 24th, 2014 (the 83rd day of the year) and April 14th, 2011 (the 104th day of the year), respectively. Data also reveal considerable variation in the dates of both FD and CFD on Qinghai Lake between 2000 and 2016 as well as relatively little change in FUS times. The average lengths of FD and CFD recorded in this study were 88 days and 77 days, respectively; the longest FD was 108 days while the shortest was 69 days, and corresponding CFD values were 96 days and 55 days, respectively. It is noteworthy that the longest and shortest values for both FD and CFD were between 2010 and 2011 and between 2008 and 2009, respectively, while the average ICD for Qinghai Lake was 108 days between FUS and BUE. The longest ICD recorded was 125 days between 2005 and 2006, while the shortest was just 90 days between 2004 and 2005 and between 2015 and 2016. Data show an average AD of 10 days between BUS and BUE each year; the longest recorded AD was 26 days between 2014 and 2016, while the shortest was just four days between 2012 and 2013.

Table 1 The ice phenology of Qinghai Lake between 2000 and 2016

\begin{tabular}{|c|c|c|c|c|c|c|c|c|}
\hline Year & FUS & FUE & BUS & BUE & ICD & $\mathrm{AD}$ & FD & CFD \\
\hline $2000 / 2001$ & 343 & $6^{*}$ & 85 & $92 *$ & 114 & 7 & 86 & 79 \\
\hline $2001 / 2002$ & 351 & 5 & $92 *$ & 98 & 112 & 6 & 93 & 87 \\
\hline $2002 / 2003$ & 355 & 4 & $85^{*}$ & $89^{*}$ & 99 & 4 & 85 & 81 \\
\hline $2003 / 2004$ & $359^{*}$ & 12 & $79 *$ & 88 & 94 & 9 & 76 & 67 \\
\hline $2004 / 2005$ & $362 *$ & 10 & $69^{*}$ & $87 *$ & 90 & 18 & 79 & 59 \\
\hline $2005 / 2006$ & 340 & 357 & $86^{*}$ & $100^{*}$ & 125 & 14 & 108 & 94 \\
\hline $2006 / 2007$ & 348 & 7 & $90 *$ & 96 & 113 & 6 & 89 & 83 \\
\hline $2007 / 2008$ & 353 & $4 *$ & $97 *$ & $102 *$ & 114 & 5 & 99 & 93 \\
\hline $2008 / 2009$ & 344 & $23^{*}$ & $78 *$ & 92 & 113 & 14 & 69 & 55 \\
\hline $2009 / 2010$ & 351 & 365 & 78 & $84 *$ & 98 & 6 & 84 & 78 \\
\hline $2010 / 2011$ & 347 & 361 & $91^{*}$ & 104 & 122 & 13 & 108 & 96 \\
\hline $2011 / 2012$ & 350 & $5 *$ & 95 & 103 & 118 & 8 & 98 & 90 \\
\hline $2012 / 2013$ & 342 & 361 & 88 & 92 & 115 & 4 & 97 & 92 \\
\hline $2013 / 2014$ & 350 & 8 & 65 & 83 & 98 & 18 & 75 & 57 \\
\hline $2014 / 2015$ & 346 & 3 & $62 *$ & $88 *$ & 107 & 26 & 85 & 59 \\
\hline $2015 / 2016$ & 359 & 12 & $71^{*}$ & $84 *$ & 90 & 13 & 72 & 59 \\
\hline Average & 350 & 5 & 82 & 93 & 108 & 10 & 88 & 77 \\
\hline Range & 22 & 31 & 35 & 21 & 35 & 22 & 39 & 41 \\
\hline Slope (d/a) & -0.12 & -0.08 & -0.86 & -0.29 & -0.16 & 0.58 & -0.22 & -0.78 \\
\hline
\end{tabular}

Notes: *, denotes error date (the maximum error in this study was 3 days); FUS, FUE, BUS, and BUE times are denoted in this table by the number of days in the year (e.g., December 9 th is the 343 rd day of the year).

\subsection{Changes in lake ice phenology}

The data collated in this study reveal significant variations of ice phenology on Qinghai Lake between 2000 and 2016, in particular relatively little change in the timing of FUS; this 
phenomenon usually occurred on the 350th day of the year apart from between 2003 and 2005 and between 2015 and 2016. Variation in FUE dates can be characterized by an initial advance in time followed by a subsequent trend towards delays with the largest variation recorded approximately one month. In contrast, BUS dates tended to show the opposite trend over the course of this study; the average BUS date recorded was the 85th day of the year subsequent to 2012 but fell on the 72nd day of the year prior to this point. Although the date of BUE fluctuated little between 2005 and 2012, this date advanced within the year between 2000 and 2005 (apart from between 2001 and 2002) and between 2012 and 2016. Changes in ICD, FD, and CFD all remained basically consistent over the time period of this study; these dates all tended to initially extend within the year before falling back between 2005 and 2010, and gradually shortening in duration between 2000 and 2005 and between 2010 and 2016. Values for AD also tended to fluctuate over the course of this study, initially reducing in length before extending between 2000 and 2012. It is noteworthy that these values were always larger than average durations over the 17 years between 2012 and 2016 and they tended to advance in the year overall.

Although the results of this study are consistent with previous research, there are some differences. Trends of ice phenology in Qinghai Lake reported by Cai et al. (2016) are similar to those presented here, but the detailed dates recovered for FUS, FUE, BUS, and BUE vary for some years up to maximum differences of 9 days (between 2008 and 2009), 19 days (between 2008 and 2009), 14 days (between 2014 and 2015), and 6 days (between 2006 and 2007), respectively, because of disparity in data sources and methods. Because Cai et al. (2016) used passive microwave SMMR and SSM/I data with low spatial resolution and the artificial visual interpretation method (their results are both difficult to verify and to some extent inconsistent due to the different experience of researcher). Data show that both the FD and CFD of Qinghai Lake have been shortened over time compared with other waterbodies on the Tibetan Plateau (Ke et al., 2013; Kropáèek et al., 2013; Yao et al., 2016); these changes were especially obvious subsequent to 2012 and are characterized by a lower rate of reduction than is the case for other high-altitude lakes in the plateau hinterland, including Nam Co and other examples in the Hoh Xil region. These results may be related to the geographical location of Qinghai Lake as well as other unique attributes such as its area, shape, water depth, and salinity.

\subsection{Spatial characteristics of lake ice freeze and break processes}

Spatial patterns in lake ice freeze-up and break-up can reflect differences in depth and salinity as revealed by the fact that ice begins to form in Nam Co and in the seven other lakes in the northern Hoh Xil region in shallow-water shoreline areas before gradually expanding into deep-water areas (Qu et al., 2012; Yao et al., 2016). The processes of ice freeze-up and break-up on Qinghai Lake follow a similar pattern; Figure 3 illustrates these changes between 2015 and 2016. Observations show that Qinghai Lake begins to freeze along its eastern edge close to Haiyan Bay (Figure 3a) before ice begins to form in the northeast and northwest; at the same time, lake ice gradually expands out from the shore into the center of this waterbody (Figures $3 \mathrm{~b}, 3 \mathrm{c}$ and $3 \mathrm{~d}$ ) before a complete freeze is seen by around January 24th 2016 (Figure 3e). Observations show that the freezing process is relatively slow overall, and that the main component of Qinghai Lake ice has melted from the northeast and north- 
west by early March 2016 (Figures 3f and 3g); at the same time, ice is gradually ablated from the lakeshore to the center such that the bulk of surface coverage has completely melted (Figures 3h and 3i) by March 31st, 2016, at a faster speed compared to the freezing process. The spatial pattern of lake ice freeze-up was generally uniform over this period compared to break-up; in other words, the region in which ice first freezes also tends to be the region where it also melts first, a distinct difference from the patterns seen in Nam Co (Ke et al., 2013) and other lakes in the northern Hoh Xil region (Yao et al., 2016). Processes of lake freeze-up and ice break-up are known to be closely related to the spatial distribution of lake ice thickness (Zaikov, 1963), another key factor which should be taken into account, especially in the context of RS-based inversions of lake ice thickness and the future initiation of winter tourism on Qinghai Lake.
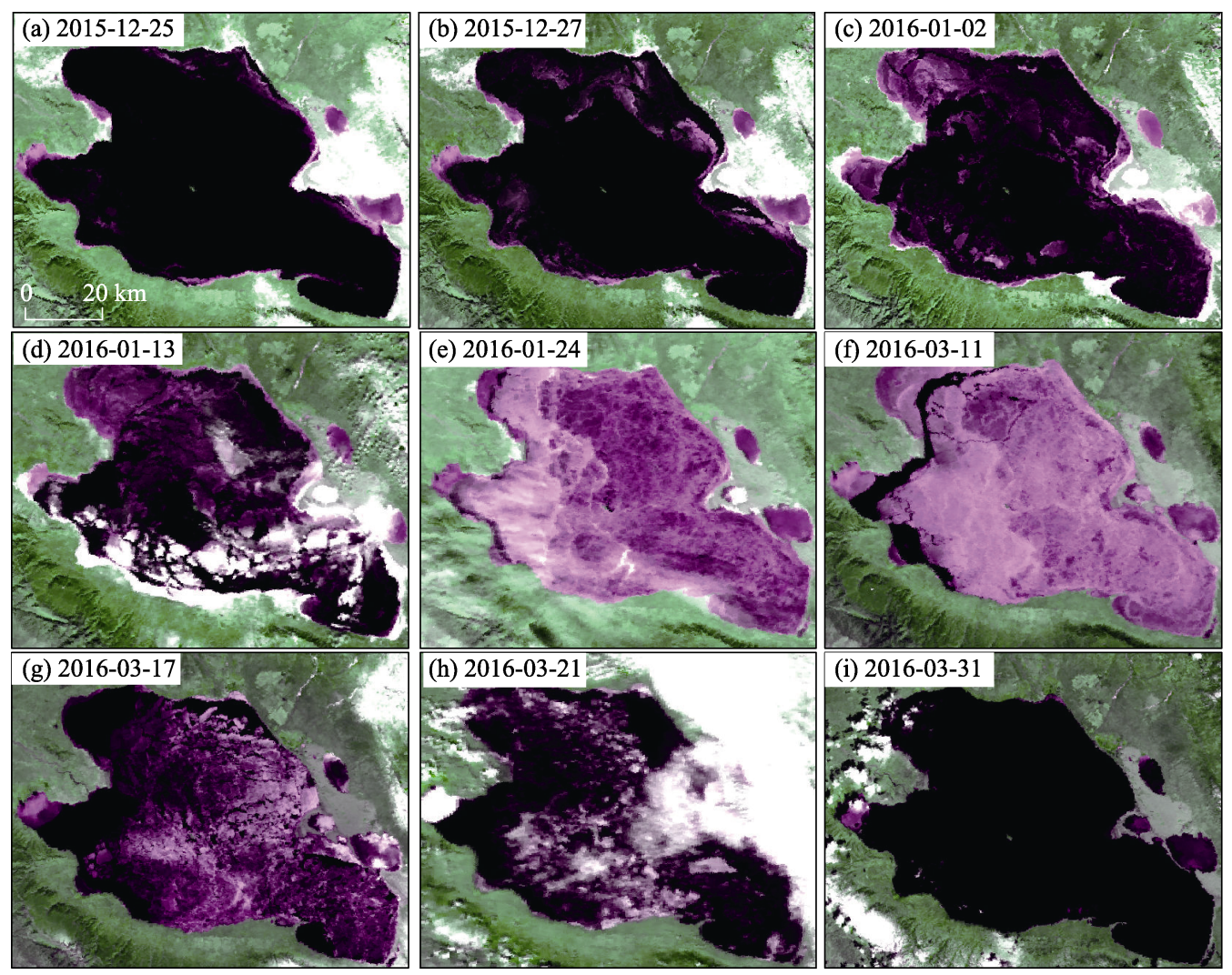

Figure 3 Images to illustrate freezing and melting processes on Qinghai Lake over time (the purple and white regions on these images are lake ice, while the black areas are water)

Observations show that the duration of lake freeze-up (between 18 days and 31 days) tends to be about 10 days longer than the duration of ice-break up (between 7 days and 20 days) overall (Figure 4). However, the lake freeze and break process were repeating and irregular in individual years. In one example, abnormal values for the ratio between ice and water areas were recorded on the 78th day of the year (Figure 4b) between 2004 and 2005; meteorological records (Figure 5a) for the same period show wind speeds of $8.8 \mathrm{~m} / \mathrm{s}$ and $10.0 \mathrm{~m} / \mathrm{s}$ on March 18th, 2005, and March 19th, 2005 (the 77th day of the year and the 78th day of the year), respectively, and reveal that temperatures began to decrease from March 
18th 2005 onwards. We therefore conclude that abnormal values may have occurred in this year due to the re-freezing of already melted lake ice as temperatures suddenly dropped and wind speeds increased. This phenomenon was also seen between 2009 and 2010 when abnormal values for the area ratio of lake ice were recorded on the 359th day, including on the 362nd day in 2009 and on the 84th day in 2010 (Figure 4c); these discrepancies can be explained by either the re-melting (or re-freezing) of already melting (or frozen) lake ice due to fluctuations in temperature or wind speed (Figures $5 \mathrm{~b}$ and $5 \mathrm{c}$ ). In terms of physical freezing and ablation processes, ice crystals and new thin ice surfaces first appear initially in shallow water around the shore of Qinghai Lake. Observations show that wind also plays an important role in lake freeze-thaw processes to the exclusion of ice surface layer optical properties and the heat of bottom waterbodies.

(a) $2000-2001$

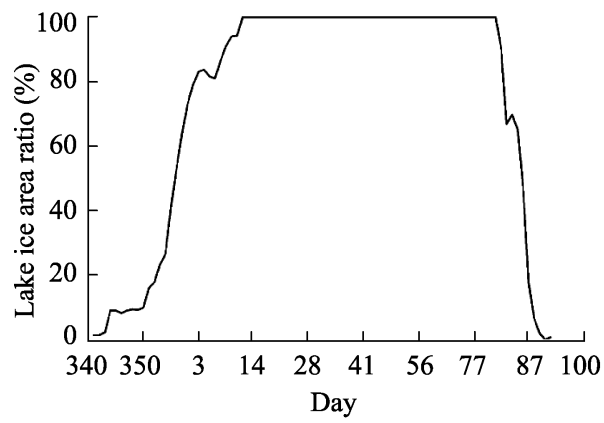

(c) $2009-2010$

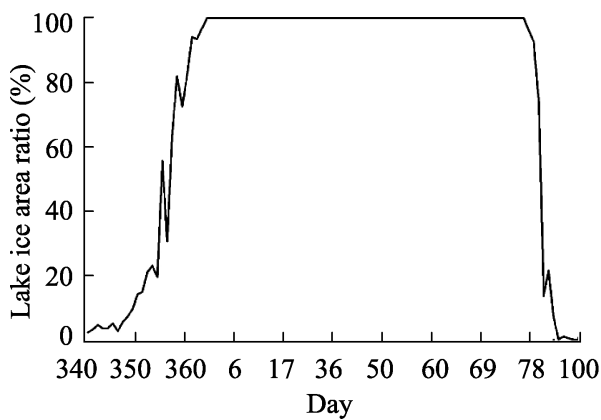

(b) 2004-2005

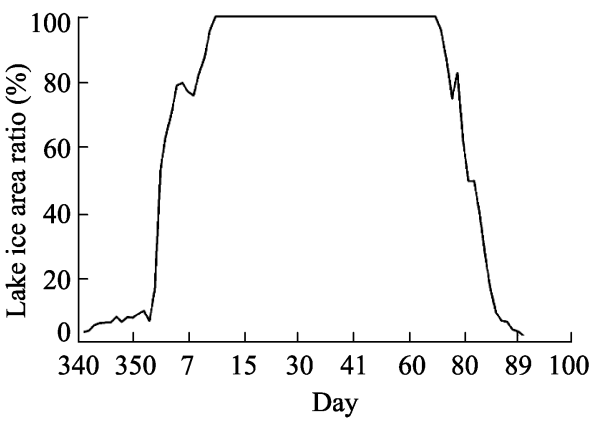

(d) 2015-2016

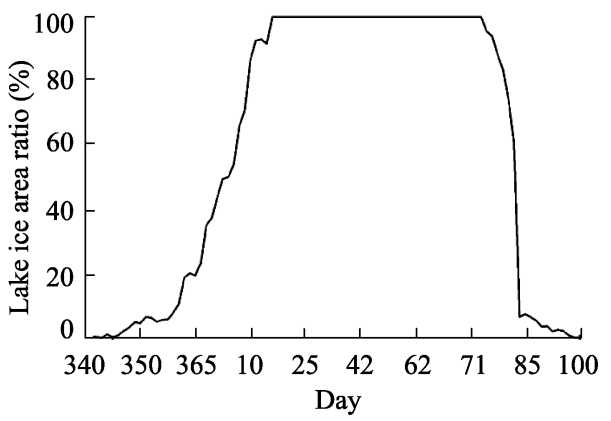

Figure 4 Qinghai Lake freeze-melt processes between 2000 and 2016

(a) March 2005

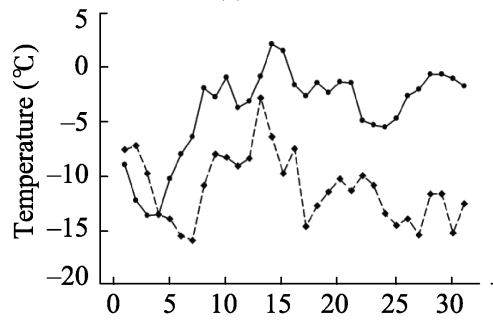

(b) December 2009

$\rightarrow$ Mean temperature

$\rightarrow$ Maximum wind speed

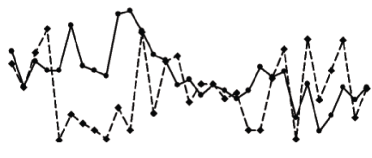

Day (c) March 2010

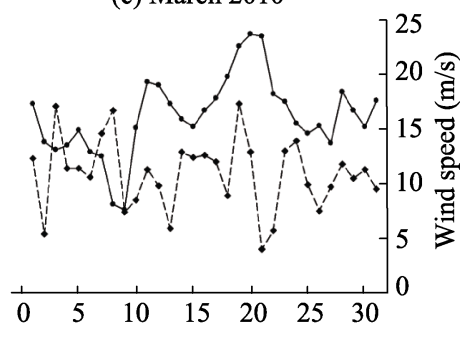

Figure 5 Daily variations in air temperature and wind speed measured at Gangcha meteorological station

As Qinghai Lake continues to cool, storms cause thinner ice to quickly crack and blow towards the shore as thin and transparent ice belts, called Shore Ice, form along the bank. The timing of continuous fixed ice formation along the margins of the lake is mainly related 
to the shape of the lakeshore and the local prevailing wind direction (Lei et al., 2011). Thus, as heat dissipation increases and fixed Shore Ice continues to form, this layer starts to extend out into the open water area of the lake; as the surface area of the open lake decreases, the formation of Shore Ice continues towards the center of the waterbody while the influence of surface wind is weakened and a continuous ice cap forms. The lake then starts to freeze in a stable fashion from the surface downwards via thermal conductivity if a constant low temperature is maintained and both ice thickness and freezing rate therefore also increase. As an ice cap forms, complete freezing of the lake is initiated even though this process is relatively slow and requires a sustained low temperature. Data show that the average temperature of Qinghai Lake remained continuously higher than $0{ }^{\circ} \mathrm{C}$ at the end of the March and into early April; at this point, the possibility of maintaining lake ice coverage is largely determined by existing heat storage within the waterbody. Lake ice subsequently begins to melt because of the influence of heat flow, while other key factors such as water level rise and wind driven ice layer breakup and increase of the contact surface area between the ice and the surrounding environment, accelerating the melting process (Duan et al., 2016; Weber et al., 2016). Observations show that wind speed and temperature at the water surface of Qinghai Lake gradually increase in March and April and also accelerate the melting process.

\subsection{The influence of climatic factors on ice conditions}

The data collated in this study reveal that the characteristics of lake ice phenology are influenced by both meteorological (e.g., temperature, solar radiation, humidity, and snow) and geographical (e.g., lake shape and location) factors. Observations show that temperature is the main factor underlying these changes over longer time scales (Dibike et al., 2012), an important result because the Tibetan Plateau is experiencing marked warming (Duan et al., 2016; You et al., 2016) at a significantly higher level than the average global rate (Kang et al., 2010). Data from 6 meteorological stations within the Qinghai Lake Basin also show that average temperature has risen significantly over the last 50 years (Sun et al., 2007); thus, changes in lake ice phenology provide a good indication of negative accumulated temperature over the course of the winter half year. In order to further discuss these changes, we defined the winter half year in the Qinghai Lake Basin as the time interval encompassing the period between October and April of the following year; as data show that daily average temperature over this time starts below $0^{\circ} \mathrm{C}$ in mid-to-late October and then rises above this point in mid-April, we calculated the sum of daily mean temperatures below freezing throughout this period and used this value as negative accumulated temperature for the winter half year. We then analyzed correlations between accumulated negative temperature and the FD of Qinghai Lake between 2000 and 2016 (Figure 6); results show a negative correlation coefficient of -0.632 when a confi-

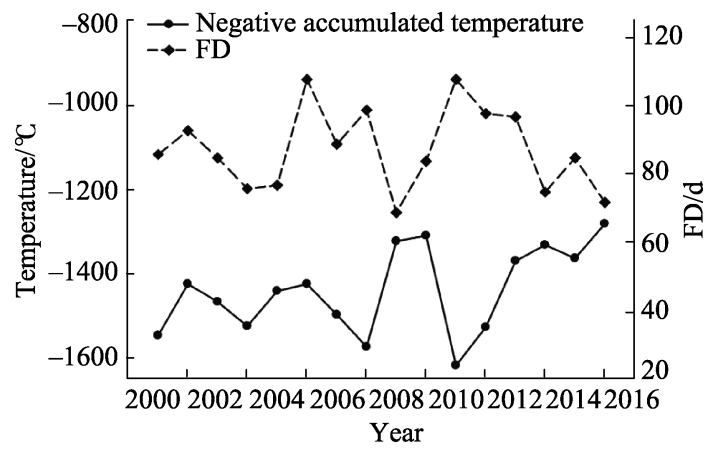

Figure 6 The relationship between winter half year negative accumulated temperature and the FD of Qinghai Lake ice between 2000 and 2016 
dence level of 0.01 was applied. This implies that Qinghai Lake has a long FD when the level of negative accumulated temperature remains small during the winter half year and a short duration when the latter variable is large. Data show that the ice phenology of Qinghai Lake responds significantly to regional climate warming and that changes in FD are a good indication for temperature during the winter half year.

Analysis of ice phenology on Qinghai Lake between 2000 and 2016 reveals clear correlations between the timing of FUS, FUE, BUS, BUE, and wind speed (Figure 7). As discussed above, we investigated these correlations by selecting average wind speeds that were measured during the week prior to lake freeze-up and break-up; the results of these comparisons reveal covariance values of $-1.57,0.57,-1.49$, and -0.93 between the four wind speed time nodes and lake ice phenology, respectively. A non-zero covariance value indicates the presence of a correlation between two variables, while negative and positive signs are indicative of corresponding relationships according to the definition of covariance (Tao, 2014). Results show that average wind speed over a week exerts an important influence on variation in Qinghai Lake ice phenology and that onset of FUS was most sensitive to changes in regional speeds; data reveal that FUS advanced when the average wind speed during a week was larger and vice versa (Figure 7a). Higher speeds accelerate convection between the air and water surface during the initial stages of ice formation and cause the heat dissipation intensity of the lake to quickly reach freezing, promoting the formation of lake ice (Lei et al., 2011). Data also show that ice BUS date was most sensitive to changes in regional wind speeds (Figure 7c), especially between 2004 and 2015; this variable was also closely related to
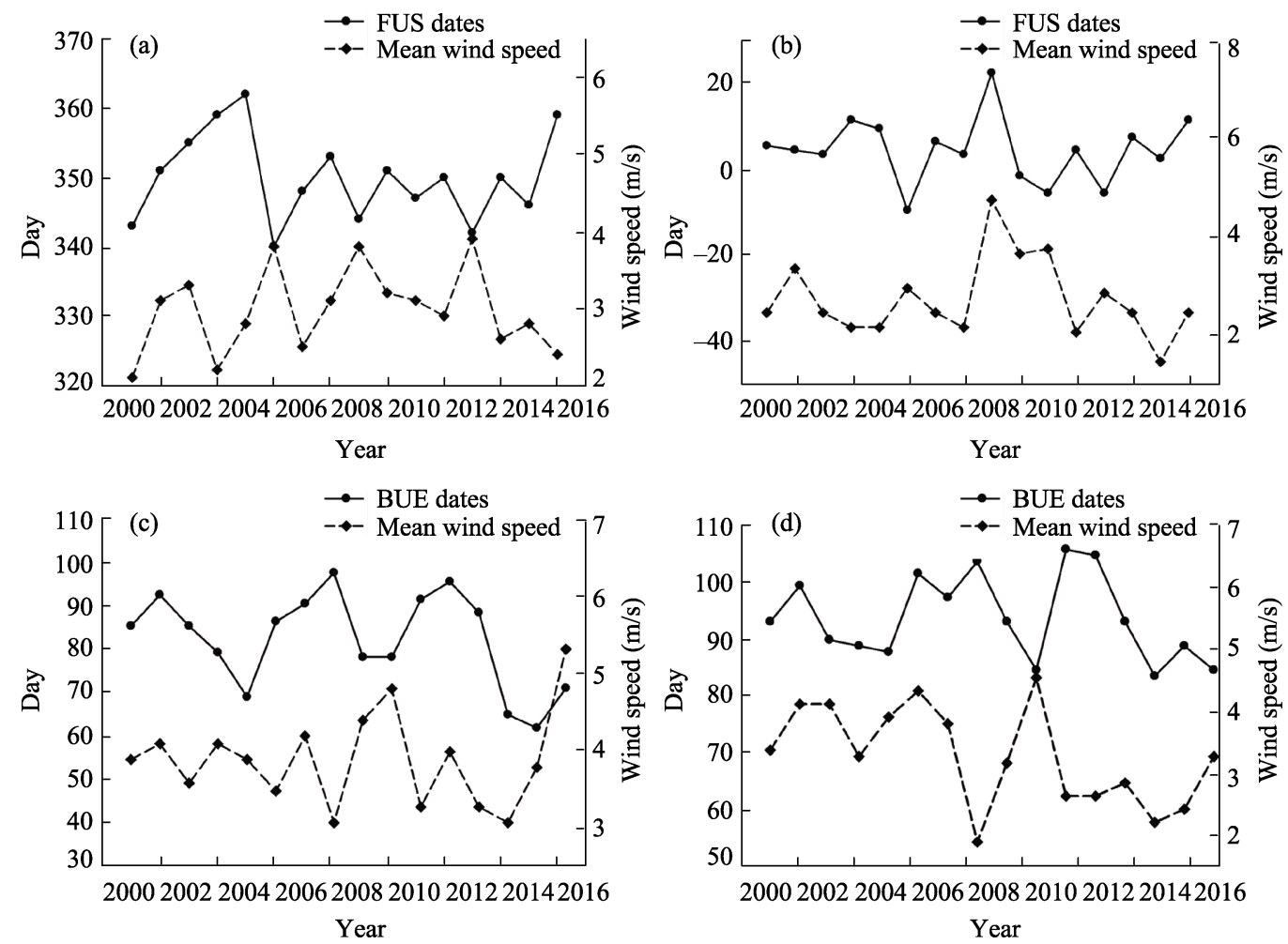

Figure 7 Graphs showing the relationship between mean weekly wind speed measured at Gangcha meteorological station and ice phenology on Qinghai Lake between 2000 and 2016 
changes in mean wind speeds within a week which shows that when average speeds were larger, ice break-up started earlier and vice versa. Indeed, because larger wind speeds can more effectively mix the water surface and hotter deeper layers, this effect slows lake surface temperature reduction to freezing while also dynamically disturbing or destroying existing ice and accelerating break-up processes (You and Kang, 2016). Analyses also show that FUE and BUE dates were not very sensitive to mean wind speeds variations within a given week, but were very responsive to variation in this factor over different time periods. In particular, FUE date responded very significantly to changes in mean wind speeds between 2003 and 2008 and between 2011 and 2016; FUE dates shifted earlier when wind speeds increased over these periods (Figure 7b). Similarly, the BUE date proved more sensitive to changes in mean wind speed between 2007 and 2016; the dates shifted to earlier in the year when wind speeds were larger and vice versa (Figure 7d).

Changes in precipitation also play a key role in the formation and ablation of lake ice in addition to other weather conditions (e.g., air temperature and wind speed). We also analyzed correlations between timings of ICD, AD, and precipitation over the same time period as part of this study. This analysis yielded correlation coefficients of -0.31 and 0.36 for ICD and $\mathrm{AD}$ versus precipitation, respectively, and data that the latter exerted a different level of influence on the two former variables. These results show that ICD was shorter during years when precipitation was larger (Figure 8a) while AD was longer (Figure 8b) and vice versa; this is likely because the temperature of the water surface remained continuously below $0^{\circ} \mathrm{C}$ between FUS and BUS while precipitation causes surface cooling and the development of crystal nuclei which are the basis of ice formation (Lei et al., 2011; Oveisy et al., 2014). As precipitation increased, ICD was shortened as faster nucleation accelerated the lake freezing process; however, the temperature of the water surface nevertheless remained lower between BUS and BUE because of increased precipitation and snowfall while the lake ice melting rate fell and ablation was prolonged.
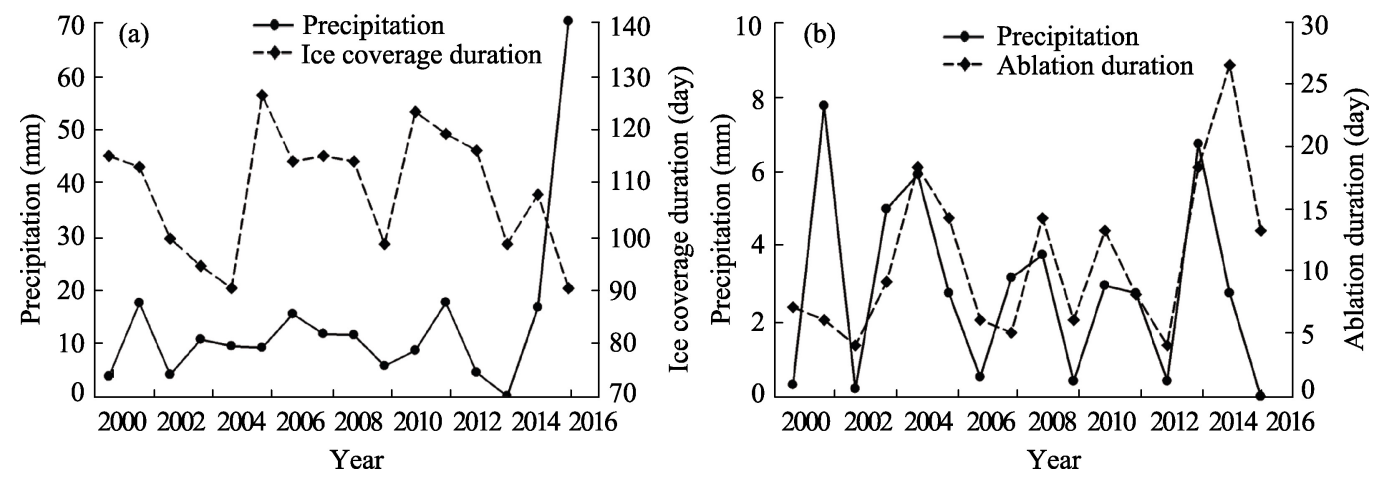

Figure 8 Graphs showing the relationship between precipitation and ice variation (coverage and ablation) on Qinghai Lake between 2000 and 2016

\section{Conclusions}

The results of this study reveal spatiotemporal variations of ice phenology on Qinghai Lake and relationships with climatic variables between 2000 and 2016.

(1) The lake ice phenology datasets presented here for the period between 2000 and 2016 
are based on MODIS MOD09GQ products. Comparisons suggest that FUS tended to occur in mid-December each year while BUS occurred in mid-to-late March of the following year. Data also show an average of 20 days between FUS and FUE with BUE occurring in early April. Average values for FD (between FUE and BUE), CFD (between FUE and BUS), ICD (between FUS and BUE), and AD (between BUS and BUE) were 88 days, 77 days, 108 days, and 10 days, respectively.

(2) Data reveal a great deal of diversity in the spatial characteristics of Qinghai Lake ice phenology between 2000 and 2016. The overall date of FUS changed relatively little over the time period of this study, while the dates of FUE and BUS trended in opposite directions. Results also show that the date for BUE between 2000 and 2005 (apart from between 2001 and 2002) and between 2012 and 2016 tended to advance within the year. Changes in ICD, FD, and CFD all remained basically consistent, these dates were initially advanced within the year but then fell back between 2005 and 2010. The durations of these periods also all gradually shortened between 2000 and 2005 and between 2010 and 2016, and AD has increased slightly over the last five years.

(3) Qinghai Lake is characterized by similar spatial patterns in freeze-up and break-up processes; observations show that ice begins to form from the eastern edge of the lake close to Haiyan Bay before the northeastern and northwestern sections of this waterbody start to freeze. At the same time, ice gradually expands out from the lakeshore into the center of lake and begins to melt from the northeast and northwest after 77 days of CFD and is gradually ablated in the same direction. Observations show that areas of the water surface that froze earlier also started to melt first on Qinghai Lake, a distinct difference from other similar waterbodies on the Tibetan Plateau. An additional feature of Qinghai Lake ice phenology is that the duration of freeze-up (between 18 days and 31 days) is on average about ten days longer than the duration of break-up (between seven days and 20 days).

(4) The data presented in this study clearly show that the ice phenology of Qinghai Lake depends on a range of climatic factors. Winter negative accumulated temperature determines the length of lake FD, for example, Qinghai Lake is characterized by a long FD when winter half year negative accumulated temperature is smaller, while wind speeds and precipitation also exert significant effects on the formation and ablation of lake ice. Higher wind speeds can promote the formation of lake ice during early stages and can also accelerate melting at this time. The effect of precipitation on lake ice is most evident during years with high rainfall; lake ice coverage duration is shorter at these times while ablation durations are longer, and vice versa.

\section{References}

Benson B J, Magnuson J J, Jensen O P et al., 2012. Extreme events, trends, and variability in Northern Hemisphere lake ice phenology (1855-2005). Climatic Change, 112(2): 299-323.

Cai Y, Ke C Q, Duan Z, 2017. Monitoring ice variations in Qinghai Lake from 1979 to 2016 using passive microwave remote sensing data. Science of the Total Environment, 607: 120-131.

Che Tao, Li Xin, Jin Rui, 2009. Monitoring the frozen duration of Qinghai Lake using satellite passive microwave remote sensing low frequency data. Chinese Science Bulletin, 54(6): 787-791. (in Chinese)

Chen Xianzhang, Wang Guangyu, Li Wenjun et al., 1995. Lake ice and its remote sensing monitoring in the Tibetan Plateau. Journal of Glaciology and Geocryology, 17(3): 241-246. (in Chinese) 
Choinski A, Kolendowicz L, Pociask K J et al., 2010. Changes in lake ice cover on the Morskie Oko Lake in Poland (1971-2007). Advances in Climate Change Research, 1(2): 71-75.

Dibike Y, Prowse T, Bonsal B et al., 2012. Simulation of North American lake-ice cover characteristics under contemporary and future climate conditions. International Journal of Climatology, 32(5): 695-709.

Dong H M, Song Y G, 2011. Shrinkage history of Lake Qinghai and causes during the last 52 years. In: International Symposium on Water Resource \& Environmental Protection (ISWREP), 446-449.

Duan Anmin, Xiao Zhixiang, Wu Guoxiong, 2016. Characteristics of climate change over the Tibetan Plateau under global warming during 1979-2014. Progressus Inquisitiones De Mutatione Climatis, 12(5): 374-381. (in Chinese)

Duguay C R, Prowse T D, Bonsal B R et al., 2006. Recent trends in Canadian lake ice cover. Hydrological Processes, 20(4): 781-801.

Gou Peng, Ye Qinghua, Wei Qiufang, 2015. Lake ice change at the Namco Lake on the Tibetan Plateau during 2000-2013 and influencing factors. Progress in Geography, 34(10): 1241-1249. (in Chinese)

Hall D K, Riggs G A, 2002. MODIS snow-cover products. Remote Sensing of Environment, 83(1): 181-194.

Johnson S L, Stefan H G, 2006. Indicators of climate warming in Minnesota: Lake ice covers and snowmelt runoff. Climate Change, 75(4): 421-453.

Kang S C, Xu Y W, You Q L et al., 2010. Review of climate and cryospheric change on the Tibetan Plateau. Environmental Research Letters, 5(1): 015101. Doi: 10.1088/1748-9326/5/1/015101.

Ke C Q, Tao A Q, Jin X, 2013. Variability in the ice phenology of Nam Co Lake in central Tibet from scanning multichannel microwave radiometer and special sensor microwave/imager: 1978 to 2013. Journal of Applied Remote Sensing, 7(1): 073477. doi: 10.1117/1.JRS.7.073477.

Kropáček J, Maussion F, Chen F et al., 2013. Analysis of ice phenology of lakes on the Tibetan Plateau from MODIS data. Cryosphere, 7(1): 287-301.

Latifovic R, Pouliot D, 2007. Analysis of climate change impacts on lake ice phenology in Canada using the historical satellite data record. Remote Sensing of Environment, 106(4): 492-507.

Lei Ruibo, Li Zhijun, Zhang Zhanhai et al., 2011. Comparisons of thermodynamic processes between lake ice and landfast sea ice around Zhongshan Station, East Antarctica. Chinese Journal of Polar Research, 23(4): 289-298. (in Chinese)

Lenormand F, Duguay C R, Gauthier R, 2002. Development of a historical ice database for the study of climate change in Canada. Hydrological Processes, 16(18): 3707-3722.

Li Fengxia, Fu Yang, Yang Qing et al., 2008. Climate change and its environmental effects in the surrounding area of Qinghai Lake. Resources Sciences, 30(3): 348-353. (in Chinese)

Ma R, Yang G, Duan H et al., 2011. China's lakes at present: Number, area and spatial distribution. Science China Earth Sciences, 54(2): 283-289.

Ma Yuwei, Zhang Jingran, Liu Xiangjun et al., 2011. Lake level fluctuations in Qinghai Lake since the Last Deglaciation. Journal of Salt Lake Research, 19(3): 19-25. (in Chinese)

Magnuson J J, Robertson D M, Benson B J et al., 2000. Historical trends in lake and river ice cover in the Northern Hemisphere. Nature, 289(5485): 1743-1746.

Marszelewski W, Skowron R, 2006. Ice cover as an indicator of winter air temperature changes: Case study of the Polish Lowland lakes. Hydrological Sciences Journal, 51(2): 336-349.

Oveisy A, Boegman L, Imberger J, 2014. One-dimensional simulation of lake and ice dynamics during winter. Journal of Limnology, 73(3): 43-57.

Pan Baotian, Li Jijun. Qinghai-Tibetan Plateau: A driver and amplifier of the global climatic change III. The effects of the uplift of Tibetan Plateau on climate changes. Journal of Lanzhou University (Natural Sciences), 1996, 32(1): 108-115. (in Chinese)

Qin Dahe. Climate and Environment Change in China: 2012 Comprehensive Volume. Beijing: China Meteorological Press, 2012. (in Chinese)

Qu Bin, Kang Shichang, Chen Feng et al., 2012. Lake ice and its effect factors in the Nam Co basin, Tibetan Plateau. Progressus Inquisitiones de Mutatione Climatis, 8(5): 327-333. (in Chinese) 
Reed B, Budde M, Spencer P et al., 2009. Integration of MODIS-derived metrics to assess interannual variability in snowpack, lake ice, and NDVI in southwest Alaska. Remote Sensing of Environment, 113(7): 1443-1452.

Sun Yongliang, Li Xiaoyan, Xu Heye, 2007. Daily precipitation and temperature variations in Qinghai Lake watershed in recent 40 years. Arid Meteorology, 25(1): 7-13. (in Chinese)

Tao Anqi, 2014. Research on the variation of Namco Lake ice by passive microwave remote sensing [D]. Nanjing: Nanjing University. (in Chinese)

Vaughan D G, Comiso J C, Allison I et al., 2013. Observations: Cryosphere. In: Stocker T F, Qin D, Plattner G K et al., Climate Change 2013: The Physical Science Basis. Contribution of Working Group I to the Fifth Assessment Report of the Intergovernmental Panel on Climate Change. Cambridge: Cambridge University Press.

Wan W, Xiao P F, Feng X Z et al., 2014. Monitoring lake changes of Qinghai-Tibetan Plateau over the past 30 years using satellite remote sensing data. Chinese Science Bulletin, 59(10): 1021-1035.

Wang J, Bai X, Hu H et al., 2012. Temporal and spatial variability of Great Lakes ice cover, 1973-2010. Journal of Climate, 25(4): 1318-1329.

Wang J, Hu H, Schwab D et al., 2010. Development of the great lakes ice-circulation model (GLIM): Application to Lake Erie in 2003-2004. Journal of Great Lakes Research, 36(3): 425-436.

Weber H, Riffler M, Nõges T et al., 2016. Lake ice phenology from AVHRR data for European lakes: An automated two-step extraction method. Remote Sensing of Environment, 174: 329-340.

Wei Qiufang, Ye Qinghua, 2010. Review of lake ice monitoring by remote sensing. Progress in Geography, 29(7): 803-810. (in Chinese)

Weyhenmeyer G A, Meili M, Livingstone D M, 2004. Nonlinear temperature response of lake ice breakup. Geophysical Research Letters, 31(31): 157-175.

Xin Yufei, Bian Lingen, 2008. Progress of prediction of the global cryosphere change. Chinese Journal of Polar Research, 20(3): 671-682. (in Chinese)

Yao Xiaojun, Li Long, Zhao Jun et al., 2016. Spatial-temporal variations of lake ice in the Hoh Xil region from 2000 to 2011. Journal of Geographical Sciences, 26(1): 70-82.

Yin Qingjun, Yang Yinglian, 2005. Remote sensing monitoring of Qinghai Lake based on EOS/MODIS data. Journal of Lake Sciences, 17(4): 356-360. (in Chinese)

You Q, Min J, Kang S, 2016. Rapid warming in the Tibetan Plateau from observations and CMIP5 model in recent decades. International Journal of Climatology, 36(6): 2660-2670.

Zaikov, 1963. Introduction to Lake Science. Beijing: The Commercial Press. (in Chinese) 